\title{
Effect of seasonal photoperiod on molting in Loxosceles reclusa and Loxosceles laeta spiders (Araneae: Sicariidae)
}

\author{
Richard S. Vetter ${ }^{1}$, Linda M. Penas ${ }^{2}$ and Mark S. Hoddle ${ }^{1}$ : ${ }^{1}$ Department of Entomology, University of California, \\ Riverside, CA 92521. E-mail: rick.vetter@ucr.edu ${ }^{2}$ Department of Statistics, University of California, Riverside, CA 92521
}

\begin{abstract}
During the winter of 2014-15 in southern California, attempts were made to accelerate immature brown recluse spiders, Loxosceles reclusa Gertsch \& Mulaik, 1940, to maturity for a pest control experiment in early spring. Despite food offerings, spiders stopped molting after October although they were maintained at $25^{\circ} \mathrm{C}$ and had swollen, well-nourished abdomens. It was surmised that decreased filtered daylight from a paper-covered window might be suppressing molting. Feeding was halted in January 2015; 88 spiderlings were checked weekly for molts. Molting resumed during late March 2015 and continued through May 2015 despite no feedings. To more thoroughly elucidate photoperiod effects on molting, during the week of the September 2015 equinox, three cohorts of 10 immatures of both brown and Chilean recluses, $L$. laeta (Nicolet, 1849), were exposed to three light regimes: 14:10 L:D, natural, 10:14 L:D. Through November 2015 to late March 2016 for brown recluses, there was no molting in the 10:14 regime, 3 of 10 spiders molted in the natural light regime, and 8 of 10 spiders molted in the 14:10 L:D regime. Additionally, fifteen newly-emerged brown recluse spiderlings split into three cohorts of 5 spiders each in November exhibited more molting in the 14:10 L:D compared to natural and 10:14 L:D light cycles. Chilean reciuses showed no differences in molting across the three photoperiod regimes. This species difference may be explained in that brown recluses are native to temperate zones where winters can be fatal; Chilean recluses are tropical where short photoperiods may have little significance for survival.
\end{abstract}

Keywords: Life history traits, urban entomology, urban pest, development, recluse spiders

Spider life-history traits are often influenced by abiotic variables such as temperature, humidity, and photoperiod. Even when brought into the laboratory and exposed to conditions that are considered favorable for continued growth, seasonal cessation of development has been noted for a variety of spider taxa such as Pardosa astrigera L. Koch, 1878 (Miyashita 1969), Pisaura mirabilis (Clerck, 1757) (Dondale \& Legendre 1971), Parasteatoda tepidariorum (C.L. Koch, 1841) (Tanaka 1991, 1992) and thomisids (Schick 1965). This cessation can be labeled diapause or quiescence depending on the conditions. Diapause requires an environmental trigger such as non-adverse temperature and seasonal light cycle changes to initiate and terminate this condition, which involves endocrinology and synthesis or reduction of specific compounds (Saunders 2002). Quiescence is merely a short period of inactivity instigated by unfavorable conditions, which can be immediately reversed upon return to normal environmental factors (Saunders 2002).

The brown recluse spider, Loxosceles reclusa Gertsch \& Mulaik, 1940, was not known to be medically important in North America until 1957 (Atkins et al. 1957); soon after this date, there was a rush to present biological and medical information on the spider. Extensive life history work was documented by Hite et al. (1966) and Horner \& Stewart (1967). However, one area that has yet to be investigated is the effect of seasonal photoperiod on Loxosceles molting. Instigated by a serendipitous observation, herein we examine the response of brown recluse spiders and their tropical relatives, the Chilean recluse spider, $L$. laeta (Nicolet, 1849) to different photoperiod regimes in the laboratory.

\section{METHODS}

Spiders. - Brown recluse spiders were taken from a colony that was initiated with specimens collected in Columbia,
Missouri in 1995, with occasional genetic infusion from spiders collected in Russellville, Arkansas and Lenexa, Kansas. Chilean recluses originated from a colony that was started from specimens collected in San Gabriel (Los Angeles County) California in 2003 and had been in captivity since then without genetic infusion.

General procedures.-In all experiments, spiderlings were maintained individually in $3 \frac{1}{2}$ to 40 dram vials $(13$ to $150 \mathrm{ml})$ with plastic snap-on lids; vial volume corresponded with spiderling size. A piece of paper towel was placed inside the vial such that it covered the inner half of the vial's circumference, providing a surface for silk deposition to aid in molting as well as prey capture. When being fed, each spiderling was offered a single German cockroach, Blattella germanica, approximately the same body length as that of the spiderling.

Initial observation that instigated the study. - In the autumn of 2014 , more than 100 brown recluse spiderlings emerged from egg sacs and were separated into individual $3 \frac{1}{2}$ dram vials. Each was offered a small German cockroach twice a month, which is sufficient for growth (i.e., recluse spiders fed twice a month undergo molting), in the expectation that the spiderlings would mature by early spring for an unrelated, large-scale mating experiment. Although spiderlings were not being specifically monitored, it was observed that they ceased molting after October. None were dying and their abdomens were very well distended, similar to spiders capable of molting. These spiderlings were maintained in a room in the University of California-Riverside (UCR) Insectary and Quarantine facility that had diffuse natural lighting. The window to this room was located under a large overhang of the insectary, was covered with brown butcher paper, never received direct sunlight and was used continuously for recluse spider maintenance for several years with spiders readily molting to maturity. When molting was still not occurring by the end of 
January despite prey offerings on a twice-monthly basis, it was surmised that cessation of development might be due to the decreased natural winter light cycle.

Therefore, in attempt to determine whether molting was influenced by photoperiod, at the end of January, 88 spiderlings in their individual vials were haphazardly chosen from the cohort of $100+$. Prey offerings ceased and vials were checked once a week from 8 February 2015 until the first molt was observed (30 March 2015), after which they were checked twice a week until 31 May 2015, when this portion of the study was terminated. When a spiderling molted, it was removed from the pool because we wanted to document the first postwinter molting of each spiderling. Spiderlings were in their second to fourth instars at the initiation of the experiment in early February. Room temperature was maintained at approximately $25^{\circ} \mathrm{C}$ year-round, but not recorded.

Effect of photoperiod on molting.-In September 2015, immature brown and Chilean recluse spiders $(n=30$ of each species) were arranged from smallest to largest in approximate size within each species and assigned to three cohorts via numbers randomly generated in triplets (i.e., 213, 132, 312, etc.) so that each experimental cohort within each species would have an approximately similar range of spider sizes and, hence, approximately the same demographics of instars. Penultimate males were not used. Based on experience in rearing hundreds of recluses from egg sacs, it was estimated that the spiderlings ranged from the third to seventh instars. This spectrum was chosen in order to have representatives from various instars involved in the bioassay instead of biasing it toward one particular instar; in insects, different instars within a species can have differential proclivity to entering diapause (Tauber et al. 1986). For each species, one cohort of ten spiderlings was assigned to a 14:10 L:D light cycle exposure, the second to a 10:14 L:D light cycle and the third to a natural light cycle through a brown paper-covered window. The UCR campus where experiments were conducted is located at $33^{\circ} 57^{\prime} \mathrm{N}$ latitude and approximately experiences seasonal $14: 10$ and 10:14 photoperiod extremes. Prior to the start of the experiment, spiderlings were maintained in a room in the Insectary and Quarantine Facility at UCR with an ambient photoperiod and offered $B$. germanica about once a month. The last pre-assay meal occurred between 11 to 13 September 2015 when spiderlings were transferred to clean vials.

The photoperiod experiment was initiated on 26 September 2015,5 days after the autumn equinox when the light cycle was approximately 12:12 L:D, at which point, spiderlings were offered $B$. germanica again and assigned to one of the three experimental cohorts. The 14:10 and 10:14 L:D cohorts were placed inside plywood boxes, $45 \mathrm{~cm}$ height $\mathrm{x} 45 \mathrm{~cm}$ width by $60 \mathrm{~cm}$ length with a piece of white opaque plastic ( $3 \mathrm{~mm}$ thick) placed at the $45 \mathrm{~cm}$ mark inside the box, constituting the back wall, and covered with a lid (Fig. 1). A light socket with a 4watt frosted nightlight bulb (EverydayLiving, Kroger Co., Cincinnati $\mathrm{OH}$ ) was positioned behind the plastic on the posterior $15 \mathrm{~cm}$ of the box such that light passing through the plastic was diffuse. Light levels during the day were 145 lux in the 14:10 and 10:14 L:D boxes and varied in the natural box from 44 lux on an overcast morning to 145 lux on a sunny afternoon as measured with a light meter (Gossen Luna-Pro

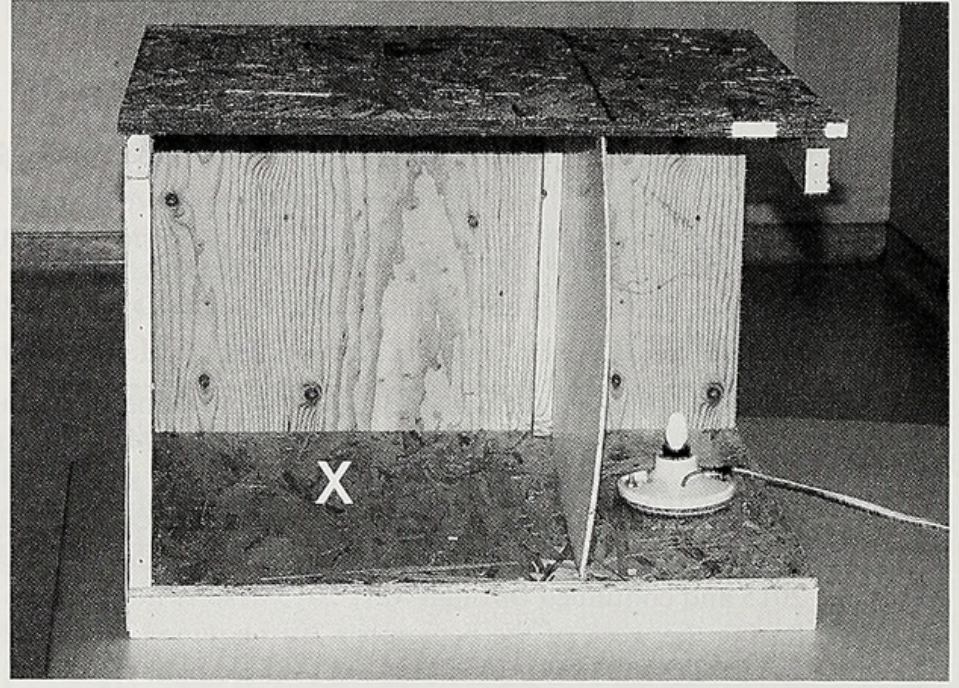

Figure 1.-View of the plywood box that housed either the 14:10 or 10:14 light cycle cohorts of spiders. The right wall of the box (facing the camera) is removed for photographic purposes. The light was placed outside of the area of the box housing the spiders and was open to the back. Spiders, in vials, were placed near the " $X$ ".

SBC, Manfrotto Distribution, Upper Saddle River, NJ). During the day, room contents were readily visible, whereas at night, the room was completely dark to the human eye, hence, providing a definite day/night cycle.

The box fronts faced each other such that light at the back of each box was emitted toward a wall covered with black construction paper, reducing reflected light, which was further obstructed with pieces of cardboard so that light should not have been visible to spiderlings in the other boxes. On the day the experiment was initiated, timers (Woods model 50008 indoor 7-day timer 2-C, Coleman Cable, Waukegan, Illinois) programmable to the minute, provided one cohort of each Loxosceles species with $121 / 4$ hours of light, increasing the light period by 15 minutes per week until reaching the 14:10 L:D level at week 7 (14 November 2015), while, conversely, a second cohort of each species was initially provided with $113 / 4$ hours of light, decreasing the light period by 15 minutes per week until the 10:14 L:D level was reached also on 14 November 2015. These light levels were then maintained until the experiment was terminated on 28 May 2016. The two cohorts (one each of $L$. reclusa and $L$. laeta) receiving natural light were placed in a cardboard box positioned flush against the paper-covered window. The room temperature was $24.8 \pm$ $0.35^{\circ} \mathrm{C}$ for the duration of the experiment. Vials were checked for remnant exuviae each week from 3 October 2015 until 28 May 2016. Spiderlings were offered $B$. germanica every week for the first 3 weeks and then at 2-week intervals for the remainder of the experiment. If a cockroach was still alive at the subsequent prey offering, the spiderling was not offered additional prey. Likewise, a spiderling was not offered prey if its legs were dark (indicating that molting was imminent within a few days), or if its legs were pale in the presence of a recently shed skin (indicating it had molted in the previous 2 days) as it could be vulnerable to roach predation (Vetter \& Rust 2010). On 27 November 2015, all spiderlings were transferred to clean vials with new pieces of paper toweling because of the buildup of shed skins, silk and dead roaches; if 


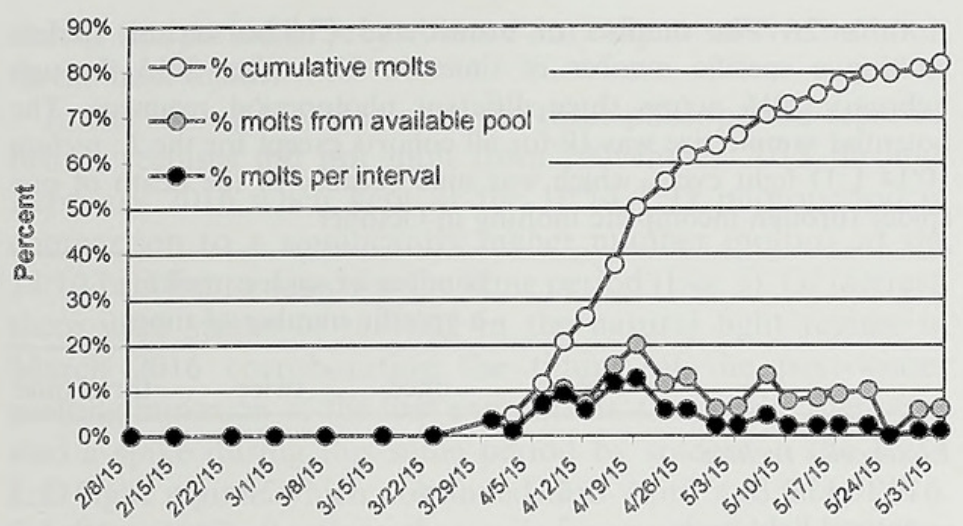

Figure 2.-Molting phenology of a pool of 88 brown recluse spiderlings exposed to a natural light cycle. The spiderlings had not molted from November 2014 to January 2015 despite being offered prey, then were not fed from February 2015 onward. Spiderlings were checked weekly until the first molt occurred on 30 March 2015, thereafter checked twice weekly through the end of May 2015. Molts per interval $(\%)$ and cumulative molts $(\%)$ are in reference to the original 88 spiderlings.

warranted due to growth via molting, spiderlings were transferred to larger vials (i.e., the diameter of the vial to which the spider was transferred was noticeably larger than the leg span of the spider such that it should not have been cramped for space). This movement of spiderlings to clean vials and new paper towels was subsequently performed on 23 January and 19 March 2016 (during a week between prey offerings). When males matured, they were removed from the experiment as they had reached their terminal life stage; suspected mature females were left in the experiment in case they were still penultimates.

Source of additional spiderlings. - Spiderlings emerged from one brown recluse egg sac during the week ending on 14 November 2015. Fifteen second-instar spiderlings were individually transferred to $3 \frac{1}{2}$ dram vials on 17 November 2015 , were randomly separated into three cohorts of five spiderlings each the next day and added to the 14:10, natural and 10:14 light cycle boxes. They were offered roaches for the first time on 21 November 2015 during the regular feeding week for the Loxosceles spiderlings described in the previous photoperiod experiment and, thereafter, each was offered a cockroach

a

Loxosceles reclusa

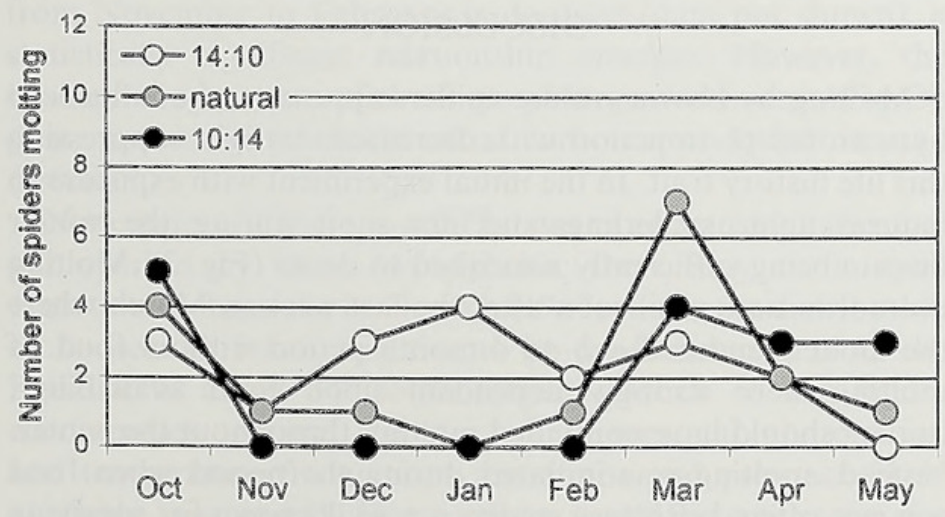

every two weeks, similar to the spiders in the assay above. These additional spiderlings were similarly checked for molting once a week. These spiderlings were of interest because they had not experienced the normal seasonal light cycle after emerging from the egg sac in comparison to the spiderlings in the previous experiment which experienced several weeks at an ambient light cycle leading up to the autumn equinox on 21 September 2015.

Statistics.-Data regarding differences among the numbers of spiders molting in the three light cycle regimes were analyzed with Fisher's Exact Test because of the large percentage of small expected frequencies; hence, only $P$ values are reported. Data were analyzed using the statistical package SAS.

\section{RESULTS}

Initial observation that instigated the study.- Spiderlings exposed to a natural light cycle and with termination of feeding at the end of January 2015 were first detected to molt on 30 March 2015 when exuviae were noted in three vials (Fig. 2). At least one newly-molted spiderling was detected at every twice-weekly check until 24 May 2015 when the pool of potential molters had decreased from 88 to 18 . The highest level of molting occurred during a 7-day period (12-19 April 2015) where 21 spiderlings molted ( $32.3 \%$ of the spiderlings in the potential pool at week's start). When this bioassay was terminated at the end of May 2015, 17 spiderlings (19.3\%) had yet to molt. Of the original 88 spiderlings, none died during this bioassay because of unsuccessful molting or starvation despite the lack of prey for those who had not eaten for up to 4 months.

Effect of photoperiod on molting in brown recluse spiders. In October 2015, the first full month under the three different light cycles (the manipulated light cycles were still being increased in the 14:10 L:D regime and decreased in the 10:14 $\mathrm{L}: \mathrm{D}$ regime), there was no statistical difference among brown recluses in regard to the number of spiders molting ( $P=0.89$, Fig. 3a, Table 1). However, during the period from November 2015 through February 2016, eight brown recluses in the 14:10 L:D photoperiod molted 10 times ( 6 once, 2 twice), 3 of 10 from the natural light cycle molted once and no moltings

b

Loxosceles laeta

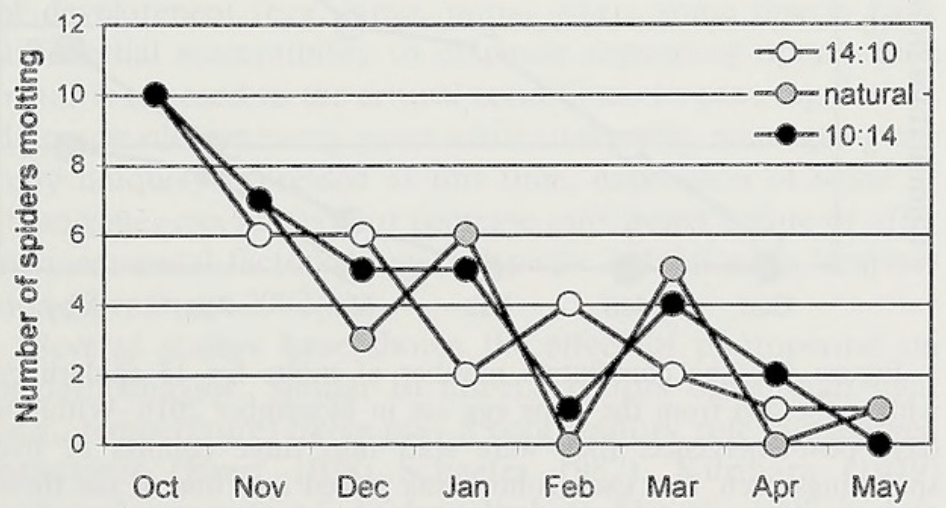

Figure 3.-(a) The number of brown recluse spiders molting each month from October 2015 through May 2016 under three light cycle regimes. (b) The number of Chilean reciuse spiders molting each month from October 2015 through May 2016 under three light cycle regimes. 
Table 1.-The number of brown and Chilean recluse spiders molting in October 2015 and in November 2015 through February 2016 across three photoperiod regimens. Sample size was 10 for all cohorts except for the L. reclusa 10:14 L:D light cycle from November to February, which was nine because of the death of one spider through incomplete molting in October. In parentheses is the number of molts undergone by the spiders in the cohort during that period.

\begin{tabular}{lcc}
\hline & Oct 2015 & Nov 2015 to Feb 2016 \\
\hline $\begin{array}{l}\text { Loxosceles reclusa } \\
\text { 14:10 L:D }\end{array}$ & $3(3)$ & $8(10)$ \\
natural light cycle & $4(4)$ & $3(3)$ \\
10:14 L:D & $5(5)$ & 0 \\
Loxosceles laeta & $10(11)$ & $9(18)$ \\
14:10 L:D & $10(10)$ & $10(16)$ \\
natural light cycle & $10(10)$ & $10(18)$ \\
10:14 L:D & & \\
\hline
\end{tabular}

occurred in the nine brown recluses in the 10:14 L:D light cycle. (The tenth spider in this last cohort died while molting in October.) This difference in the number of individual brown recluses molting in the three light regimes during November 2015-February 2016 is statistically significant $(P<0.001$, Table 1). However, one curious result was that for the natural and 10:14 L:D cycles, there was a spike in molting in March 2016 (Fig. 3).

Second instar spiderlings that emerged from an egg sac in November and were introduced into the three photoperiod regimes 4 days later showed a significant effect of light cycle exposure on molting ( $P=0.001$, Fig. 4). The five spiderlings in the 14:10 L:D light cycle each molted twice during the winter (December to February) whereas there was no molting by the spiderlings in the natural and 10:14 L:D light cycles during the same period. Spiderlings kept at the natural light cycle had two molts to the third instar detected on each of 26 March and 9 April 2016, and the 10:14 L:D light cycle had two molts detected to the third instar on each of 9 and 23 April 2016. At the termination of the experiment, the 14:10 L:D cohort

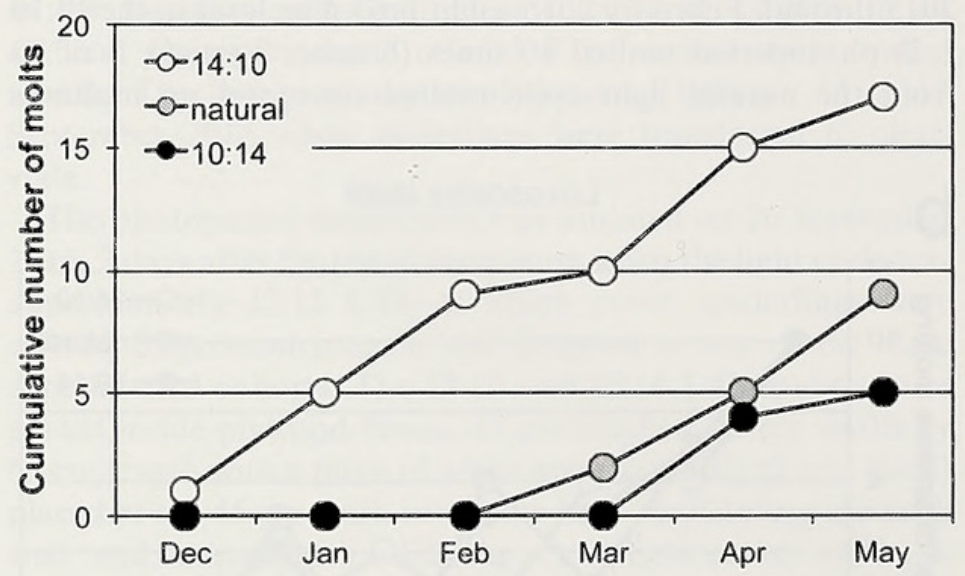

Figure 4.- The cumulative number of molts for 15 spiderlings which emerged from the same egg sac in November 2016. Within 4 days post-emergence, they were split into three cohorts of five spiderlings each, and each cohort was placed into one of the three experimental photoperiod regimes. The ordinate axis is in units of five such that each horizontal separation correlates exactly to a specific instar.
Table 2.- The number of brown and Chilean recluse spiders molting a specific number of times in November 2015 through February 2016 across three different photoperiod regimens. The potential sample size was 10 for all cohorts except for the L. reclusa 10:14 L:D light cycle, which was nine because of the death of one spider through incomplete molting in October.

\begin{tabular}{lllll}
\hline & \multicolumn{4}{c}{$\begin{array}{c}\text { Number of spiders molting } \\
\text { a specific number of times }\end{array}$} \\
\cline { 2 - 5 } & zero & once & twice & three time \\
\hline $\begin{array}{l}\text { Loxosceles reclusa } \\
\text { 14:10 L:D }\end{array}$ & 2 & 6 & 2 & \\
natural light cycle & 7 & 3 & 0 & 0 \\
10:14 L:D & 9 & 0 & 0 & 0 \\
Loxosceles laeta & & & & \\
14:10 L:D & 1 & 2 & 5 & 2 \\
natural light cycle & 0 & 4 & 6 & 0 \\
10:14 L:D & 0 & 3 & 6 & 1 \\
\hline
\end{tabular}

consisted of two $6^{\text {th }}$ instars and three $5^{\text {th }}$ instars, the natural light cycle cohort consisted of four $4^{\text {th }}$ instars and one $3^{\text {rd }}$ instar and the 10:14 L:D cohort consisted of four $3^{\text {rd }}$ instars with one death going into the $3^{\text {rd }}$ instar (Fig. 4).

Effect of photoperiod on molting in Chilean recluse spiders. In contrast to brown recluses, Chilean recluses continued to molt throughout the winter regardless of light cycle although they did so at a decreased rate from October, when every spider molted at least once (Table 1). No significant differences were detected among the three light cycles, with 29 of the 30 spiders molting at least once from November to February ( $P=1$, Table 1, Fig. 3b). Likewise, for the Chilean recluses the pool of potential molters decreased with time as spiders matured. There was also a spike in molting in the natural and 10:14 L:D spiders in March 2016 similar to that observed for the brown recluses.

Comparison of the two recluse spider species. - In the period from November 2015 to February 2016, there were no differences in the number of brown and Chilean recluses molting a specific number of times (none, once, twice, or three times) in the 14:10 L:D light cycle $(P=0.131$, Table 2$)$. However, a significantly greater number of Chilean recluses molted more often than brown recluses in the natural $(P=$ 0.001 , Table 2$)$ and 10:14 L:D light cycles $(P<0.0001$, Table 2).

\section{DISCUSSION}

Molting by brown recluse spiders appears to be influenced by seasonal photoperiod with decreased daylight suppressing this life history trait. In the initial experiment with exposure to natural light, spiderlings did not molt during the winter despite being sufficiently nourished to do so (Fig. 2). Molting did not initiate until soon after the last week in March where the molters endured a 2- to 4-month period without food. If molting were strongly dependent upon food availability, spiders should have continued molting throughout the winter. Instead, molting was initiated during the period when food was not offered. Recluse spiders are well known for surviving long periods without food (Eskafi et al. 1977; Lowrie 1980) and most of the spiderlings retained sufficient body stores 
during this period of prey absence not only to survive but molt to the next instar.

In the second bioassay with the three photoperiod regimes, brown recluses did not molt from November 2015 through February 2016 when kept at the 10:14 L:D photoperiod in comparison to a significantly higher number molting at the 14:10 L:D light regime for the same period (Fig. 3). Of interest, there were spikes of molting in the natural light regime in March 2016 corroborating the timing of the post-winter molting initiation of the first experiment. Curiously, there was also a spike during this same period by spiders in the 10:14 L:D light regime which continued into April and May 2016. Schaefer (1987) mentions that endogenous rhythms may play a role in seasonal initiation of spider development so even short photoperiods may not be sufficient to permanently suppress molting. This is corroborated in insects which lose sensitivity to photoperiod as diapause progresses (Tauber et al. 1986).

The most compelling evidence for effects of seasonal light was observed when brown recluse spiderlings were introduced to differing photoperiods soon after emergence from the egg sac. All five spiderlings in the 14:10 L:D photoperiod molted at least twice during the winter before any molting occurred in the natural or 10:14 L:D photoperiod (Fig. 4). The cohort of five spiderlings in the natural light cycle did not exhibit their first molt until the end of March 2016, the same time of year as the cohort of 88 spiderlings first molted in the previous year, corroborating the stimulus of the natural light level around the time of the spring equinox. Both of these experiments are consistent with the observations of behavioral cessation in a synanthropic population of brown recluses in an unheated Illinois garage where spiders were not actively seen from midOctober to mid-May (Cramer 2015). In comparison, molting in the Chilean recluse is much less affected by photoperiod as they continued to molt throughout the winter months albeit at a lower rate than in October (Fig. 3).

Although this experiment did not detect a significant effect of light cycle on the Chilean recluse, it is possible that this was due to small sample size. In addition, there is the confounding factor that these spiders also molted more frequently in winter than brown recluses, and because of the experimental design of using a range of ages, some $L$. laeta spiders molted to maturity during the course of the experiment, removing themselves from the sample pool. As an artificial exploratory exercise, if the number of $L$. laeta spiders that molt per month from November to February is doubled (data not shown), a statistically significant relationship emerges. However, the criss-crossing pattern of the three photoperiod lines in Fig. 3b does not indicate much of a conspicuous trend in any direction.

Nonetheless, if there is a difference in response to seasonal photoperiod by these two species, there may be a valid evolutionary basis for it. Gertsch (1967) shows the distribution of $L$. laeta in South America to be predominantly from the Equator to about $34^{\circ}$ south latitude. Much of this region encompasses tropical climates where seasonal photoperiod and temperature fluctuations are minor and prey are likely available year round. Hence, there would be no reason for cessation of activity in the "winter" months of reduced photophase for a species that evolved in the tropics.
Additionally, only the spiders at the southernmost portion of its range would experience a 10:14 photoperiod which still would place them in regions with moderate winter temperatures. In contrast, Gertsch \& Ennik (1983) show the indigenous distribution of $L$. reclusa to occur from approximately $28^{\circ}$ to $41^{\circ}$ north latitude in North America. Therefore, areas of dense brown recluse habitat are subject to predictable extreme winter conditions with snow cover and subfreezing temperatures in many portions of their natural range, such that the winter light cycle suppresses molting, in contrast to the tropical Chilean recluse which may be active year-round. Somewhat similarly, Tanaka (1992) demonstrated that subtropical Parasteatoda tepidariorum spiders from a lower latitude in Japan readily molted to maturity at a photoperiod with decreased light levels that inhibited development in the same species collected from a more temperate and higher latitude location.

In comparison to spiders, diapause in insects has been so well studied for decades that books have been dedicated to the topic (e.g., Brown \& Hodek 1980; Tauber et al. 1986; Saunders 2002). Years ago, authors documented the growing number of insect species that underwent diapause but that gave way to an acceptance that almost every insect exhibited diapause, and it was the rare creature that did not (Saunders 2002). Most insect diapause seems to be tied to light cycle, which is a reliable seasonal indicator, but diapause can also be modified or influenced by temperature, humidity or rainfall. Diapause even occurs to some degree for insects near the equator, where light cycle does not vary much from 12:12 L:D; here diapause may be significantly influenced by seasonal rainfall patterns (Tauber et al. 1986; Saunders 2002). Photoperiod influences pre-diapause factors such as fat deposition and accumulation of cryoprotectants, which occurs well before induction initiates (Adedokun \& Denlinger 1985; Denlinger 2002).

With the voluminous insect literature, it is possible to find almost every permutation of diapause factors. Examples include: (1) induction and/or termination by photoperiod, which can be dictated by the absolute photoperiod length; (2) induction by photoperiod, which can be dictated by the degree of change in photoperiod regardless of actual light cycle; (3) induction by photoperiod but termination requiring a specific number of days at low temperatures at critical periods of diapause; (4) induction by photoperiod but endogenous termination instigated after a specific time period, even when held under conditions that induce diapause initially; (5) stage of development (egg, larva, pupa) where some insects have differential susceptibility to diapause depending upon which instar is exposed to the critical conditions. In gene regulation, diapause silences many genes while conversely, some genes are only uniquely expressed at this time; expression of some of these genes can increase or decrease only hours before or after environmental factors trigger diapause induction or termination (Denlinger 2002).

Several studies have shown the effect of photoperiod on spider behavior. Similar to insects, factors other than light (e.g., temperature) likely play a contributory role in observed behaviors (Baert 1978; Schaefer 1987). Kurihara (1979) collected egg sacs of Agelena limbata Thorell, 1897 in late September and transferred them from natural conditions to the laboratory $\left(20^{\circ} \mathrm{C}, 70 \% \mathrm{RH}\right)$. On the first day that molting 
to the second instar was noticed as the spiderlings were entering winter diapause, the egg sacs were assigned to seven light regimes, varying from 10 to 16 hours of light. Ninety-five to $100 \%$ of sacs maintained at $\geq 13 \frac{1}{2}$ hours of light per day had spiderling emergence within 26 to 39 days, whereas egg sacs maintained at $\leq 13$ hours of light had only $5 \%$ to $31 \%$ emergence after 140 to 165 days. Short day light cycles can inhibit female reproductive development in spiders, which can be reversed by exposure to long-day light cycles or cold temperatures (Schaefer 1987). Miyashita (1969) collected Pardosa astrigera (cited as Lycosa T-insignita) in Japan from November to March; those spiders collected later in this period were able to molt to maturity in the laboratory sooner after long photoperiod exposure than spiders collected earlier. This long photoperiod was purported to break winter diapause and enhance progression to the mature molt by spiders that were starting to respond to longer natural daylength. Tanaka (1991) demonstrated that Parasteatoda tepidariorum spiderlings developed faster under long photoperiods than short ones with a comparatively greater delay in the ultimate molt to maturity in the short photoperiod. Response to seasonal photoperiod may be species specific where several (e.g., Pholcus phalangioides (Fuesslin, 1775), Bathyphantes gracilis (Blackwall, 1841), Pachygnatha clercki Sundevall, 1823) show similar rates of development regardless of photoperiod regime. In contrast, postembryonic development in others (e.g., Pirata piraticus (Clerck, 1757), Tetragnatha montana Simon, 1874, Oedothorax retusus (Westring, 1951)) is retarded by short photoperiods (Schaefer 1976 as cited in Schaefer 1987).

The information provided by this study may be useful beyond extending our academic knowledge on the life history of recluse spiders. The motivation for this work was to generate a large number of mature spiders by the early part of their active season in order to conduct experiments. This may not be possible if photoperiod in the laboratory is not manipulated appropriately. Researchers using recluse spiders, especially brown reciuses, should consider the effect of photoperiod on colony growth and subsequent maintenance.

\section{ACKNOWLEDGMENTS}

We thank Imad Bayoun and Serguei Triapitsyn (UCR Entomology) for allowing the use of the UC Riverside Insectary and Quarantine Facility where the assays were run. Thanks also to Ruth Amrich (UCR Entomology) for assistance in the experiments.

\section{LITERATURE CITED}

Adedokun, T.A. \& D.L. Denlinger. 1985. Metabolic reserves associated with pupal diapause in the flesh fly, Sarcophaga crassipalpis. Journal of Insect Physiology 31:229-233.

Atkins, J.A., C.W. Wingo \& W.A. Sodeman. 1957. Probable cause of necrotic spider bite in the Midwest. Science 126:73.

Baert, L. 1978. Infiuence de la photopériodicité sur la maturation ovarienne chez Gongylidium rufipes (Sundevall) (Araneae, Linyphiidae). Revue Arachnologique 2:23-27.
Brown, V.K. \& I. Hodek. 1980. Diapause and Life Cycle Strategies in Insects. Dr. W. Junk Publishers, The Hague, The Netherlands.

Cramer, K.L. 2015. Activity patterns of a synanthropic population of the brown recluse spider, Loxosceles reclusa (Araneae: Sicariidae), with observations on feeding and mating. Journal of Arachnology 43:67-71.

Denlinger, D.L. 2002. Regulation of diapause. Annual Review of Entomology 47:93-122.

Dondale, C.D. \& R. Legendre. 1971. Winter diapause in a Mediterranean population of Pisaura mirabilis Clerck. Bulletin of the British Arachnological Society 2:6-10.

Eskafi, F.M., J.L. Frazier, R.R. Hocking \& B.R. Norment. 1977. Influence of environmental factors on longevity of the brown recluse spider. Journal of Medical Entomology 14:221-228.

Gertsch, W.J. 1967. The spider genus Loxosceles in South America (Araneae, Scytodidae). Bulletin of the American Museum of Natural History 136:117-174.

Gertsch, W.J. \& F. Ennik. 1983. The spider genus Loxosceles in North America, Central America, and the West Indies (Araneae, Loxoscelidae). Bulletin of the American Museum of Natural History 175:264-360.

Hite, J.M., W.J. Gladney, J.L. Lancaster \& W.H. Whitcomb. 1966. The biology of the brown recluse spider. University of Arkansas, Fayetteville. Agricultural Experiment Station Bulletin No. 711, $26 \mathrm{pp}$.

Horner, N.V. \& K.W. Stewart. 1967. Life history of the brown spider, Loxosceles reclusa Gertsch and Mulaik. Texas Journal of Science 19:334-347.

Kurihara, K. 1979. Photoperiodic regulation of winter diapause in the grass spider. Experientia 35:1479-1480.

Lowrie, D.C. 1980. Starvation longevity of Loxosceles laeta (Nicolet) (Araneae). Entomological News 91:130-132.

Miyashita, K. 1969. Seasonal change of population density and some characteristics of overwintering nymph Lycosa T-insignita Boes. et Str. (Araneae: Lycosidae). Applied Entomology and Zoology 4:18.

Saunders, D.S. 2002. Insect Clocks. $3^{\text {rd }}$ ed. Elsevier, Amsterdam, The Netherlands.

Schaefer, M. 1976. Experimentelle Untersuchungen zum Jahreszyklus und zur Überwinterung von Spinnen (Araneida). Zoologische Jahrbücher Abteilung für Systematik Ökologie und Geographie der Tiere 103:127-289.

Schaefer, M. 1987. Life cycles and diapause. Pp. 331-347. In Ecophysiology of Spiders. (W. Nentwig, ed.). Springer-Verlag, Berlin Heidelberg.

Schick, R.X. 1965. The crab spiders of California (Araneae, Thomisidae). Bulletin of the American Museum of Natural History $129: 1-180$.

Tanaka, K. 1991. Diapause and seasonal life cycle strategy in the house spider, Achaearanea tepidariorum (Araneae, Theridiidae). Physiological Entomology 16:249-262.

Tanaka, K. 1992. Photoperiodic control of diapause and climatic adaptation of the house spider, Achaearanea tepidariorum (Araneae, Theridiidae). Functional Ecology 6:345-352.

Tauber, M.J., C.A. Tauber \& S. Masaki. 1986. Seasonal Adaptations of Insects. Oxford University Press, New York.

Vetter, R.S. \& M.K. Rust. 2010. Periodicity of molting and resumption of post-molt feeding in the brown recluse spider, Loxosceles reclusa (Araneae: Sicariidae). Journal of the Kansas Entomological Society 83:306-312.

Manuscript received 21 June 2017, revised 12 February 2017 


\section{$2 \mathrm{BHL}$ Biodiversity Heritage Library}

Vetter, Richard S., Penas, Linda M , and Hoddle, Mark S. 2017. "Effect of seasonal photoperiod on molting in Loxosceles reclusa and Loxosceles laeta spiders (Araneae: Sicariidae)." The Journal of arachnology 45(3), 277-282. https://doi.org/10.1636/joa-s-16-043.1.

View This Item Online: https://www.biodiversitylibrary.org/item/274724

DOI: https://doi.org/10.1636/joa-s-16-043.1

Permalink: https://www.biodiversitylibrary.org/partpdf/289913

\section{Holding Institution}

Smithsonian Libraries

\section{Sponsored by}

Biodiversity Heritage Library

\section{Copyright \& Reuse}

Copyright Status: In Copyright. Digitized with the permission of the rights holder

Rights Holder: American Arachnological Society

License: https://creativecommons.org/licenses/by-nc-sa/4.0/

Rights: http://www.biodiversitylibrary.org/permissions/

This document was created from content at the Biodiversity Heritage Library, the world's largest open access digital library for biodiversity literature and archives. Visit BHL at https://www.biodiversitylibrary.org. 